\title{
Primary cutaneous lymphomas: diagnosis and treatment
}

\author{
Małgorzata Sokołowska-Wojdyłoํㅜ, Karolina Olek-Hrab², Katarzyna Ruckemann-Dziurdzińska³ \\ ${ }^{1}$ Department of Dermatology, Venereology and Allergology, Medical University of Gdansk, Gdansk, Poland \\ Head of the Department: Prof. Roman Nowicki MD, PhD \\ ${ }^{2}$ Department of Dermatology, Poznan University of Medical Sciences, Poznan, Poland \\ Head of the Department: Prof. Zygmunt Adamski MD, PhD \\ ${ }^{3}$ Department of Pathology and Experimental Rheumatology, Medical University of Gdansk, Gdansk, Poland \\ Head of the Department: Prof. Ewa Bryl MD, PhD
}

Postep Derm Alergol 2015; XXXII (5): 368-383

DOI: $10.5114 /$ pdia.2015.54749

\begin{abstract}
\section{Definition}

Primary cutaneous lymphomas (CLs) are a heterogeneous group of lymphoproliferative neoplasms. Sixty five percent of CLs originate from mature $T$ lymphocytes (cutaneous T-cell lymphoma-CTCL), 25\% from mature $B$ cells (cutaneous B-cell lymphoma- $C B C L$ ) and the remaining part comprises neoplasms of natural killer cells (natural killers - NK). A lymphoma is classified as primarily cutaneous when the lymphatic proliferation is limited to the skin with no involvement of lymph nodes, bone marrow or viscera at the diagnosis.
\end{abstract}

Primary cutaneous lymphomas (CLs) are a heterogeneous group of lymphoproliferative neoplasms, with lymphatic proliferation limited to the skin with no involvement of lymph nodes, bone marrow or viscera at the diagnosis. Cutaneous lymphomas originate from mature T-lymphocytes (65\% of all cases), mature B-lymphocytes (25\%) or NK cells. Histopathological evaluation including immunophenotyping of the skin biopsy specimen is the basis of the diagnosis, which must be complemented with a precise staging of the disease and identification of prognostic factors, to allow for the choice of the best treatment method as well as for the evaluation of the treatment results.

Key words: primary cutaneous lymphoma, mycosis fungoides, Sézary syndrome.

\section{Epidemiology and etiopathogenesis}

The incidence rate of CTCL is estimated at 0.7-0.8 cases per 100000 population a year and of CBCL at approximately 0.3 per 100000 a year. Epidemiology reveals a broad diversity in the prevalence of particular CL subtypes (Table 1) [1, 2]. Cutaneous T-cell lymphomas originate mainly from the skin-homing memory CD4+CD45RO+ T cells, which have the potential to infiltrate the skin. This phenomenon is also noted for chronic inflammatory disorders, which may present with diagnostic difficulties, particularly in the initial phase of CTCL. The pathogenesis of CTCL is complex (Figures 1 and 2) [3]. Slow progression of mycosis fungoides (MF) suggests that neoplastic T cells may not initially have autonomous proliferative capacity. The loss of immunological surveillance, which allows for the clonal proliferation of mature lymphocytes in the skin, may be attributed to the changes of micro-environment, presence of polyclonal cytotoxic CD8+ T lymphocytes and dendritic cells. The migration of $T$ cells into the dermis is regulated not only by cutaneous leukocyte antigen (CLA), but also by multiple chemokines, their receptors (CCR4, CCR10, CCL17, CCL27) and cytokines (IL-15, IL-16, IL-17, IL-21, IL-22). The skin effector T cells express the cutaneous lymphocyte antigen (CLA). CLA-expressing skin-homing T cells can interact with the receptor E-selectin on dermal postcapillary venules. Furthermore, MF lesions can express high levels of CCL17 and CCL22 [3]. The proliferation of T cells is inevitably related to stimulation via CD28. Interaction between CD30 and its ligand (CD3OL), as well as between transforming growth factor $\beta$ (TGF- $\beta$ ) and its receptor, are crucial for the growth of a neoplastic clone in CD30+ lymphomas and result in alternate cycles of spontaneous remissions and relapses. The origin of NK cells in not yet fully unrevealed. It is assumed NK cells develop from a separate stem cell, differentiating from the lymphoid precursor in the bone marrow or from a double-negative (CD4-, CD8-) thymocyte, which later on leaves the thymus.

The NK cell development is thymus independent. NK cells comprise $10-15 \%$ of all lymphocytes in the periph-

Address for correspondence: Małgorzata Sokołowska-Wojdyło MD, PhD, Department of Dermatology, Venereology and Allergology, Medical University of Gdansk, 7 Debinki St, 80-211 Gdansk, Poland, phone: +48 5834925 80, fax: +48 583492586 ,

e-mail: mwojd@gumed.edu.pl

Received: 22.12.2014, accepted: 28.02.2015. 
Table 1. 2008 WHO classification of mature T, NK and B-cell primary cutaneous lymphomas

\begin{tabular}{|c|c|c|}
\hline Subtype & Frequency (\%) & 5 -year survival rate (\%) \\
\hline \multicolumn{3}{|l|}{$\mathrm{CTCL}$ - indolent clinical behaviour: } \\
\hline Mycosis fungoides (MF): & 44 & 88 \\
\hline Folliculotropic MF & 4 & 80 \\
\hline Pagetoid reticulosis & $<1$ & 100 \\
\hline Granulomatous slack skin & $<1$ & 100 \\
\hline Lymphomatoid papulosis (LyP) & 12 & 100 \\
\hline Primary cutaneous anaplastic large cell lymphoma (C-ALCL) & 8 & 95 \\
\hline Subcutaneous panniculitis-like T-cell lymphoma (SPTCL) & 1 & 82 \\
\hline Primary cutaneous small/medium pleomorphic T-cell lymphoma & 2 & 72 \\
\hline \multicolumn{3}{|l|}{ CTCL - aggressive clinical behaviour: } \\
\hline Sézary syndrome (SS) & 3 & 24 \\
\hline Primary cutaneous peripheral T-cell lymphoma, unspecified & 2 & 16 \\
\hline Primary cutaneous aggressive epidermotropic CD8 T-cell lymphoma (AECTCL) & $<1$ & 18 \\
\hline Primary cutaneous $\gamma / \delta$ T-cell lymphoma (PCGD-TCL) & $<1$ & - \\
\hline Primary cutaneous (extra-nodal) NK/T-cell lymphoma, nasal-type & $<1$ & - \\
\hline \multicolumn{3}{|l|}{ CBCL: } \\
\hline Primary cutaneous follicle centre lymphoma (PCFCL) & 11 & 95 \\
\hline Primary cutaneous marginal zone B-cell lymphoma (PCMZL) & 7 & 99 \\
\hline Primary cutaneous diffuse large B-cell lymphoma, leg type (PCLBCL) & 4 & 55 \\
\hline
\end{tabular}

CBCL - Cutaneous B-cell lymphoma, CTCL - cutaneous T-cell lymphoma.

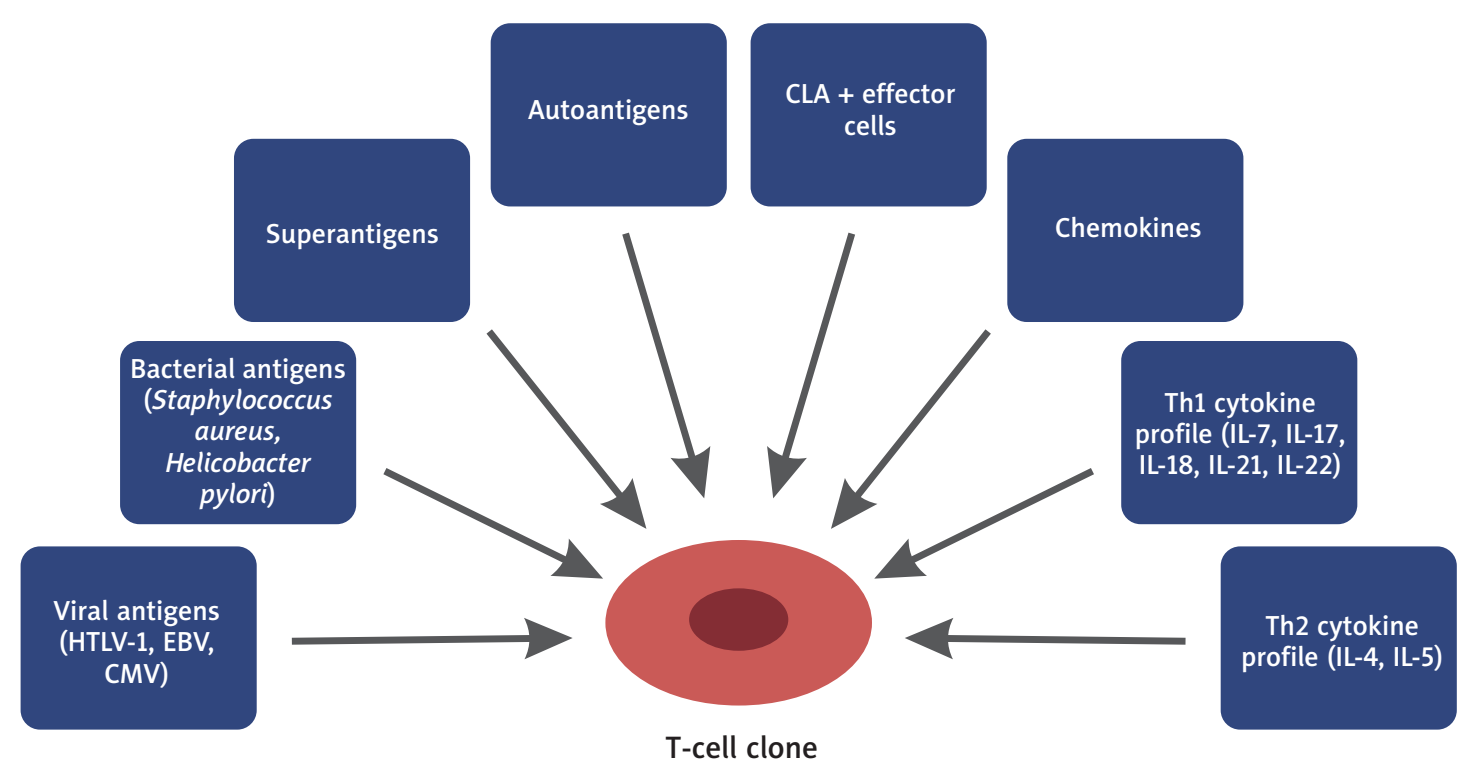

Figure 1. Pathogenesis of cutaneous T-cell lymphoma 

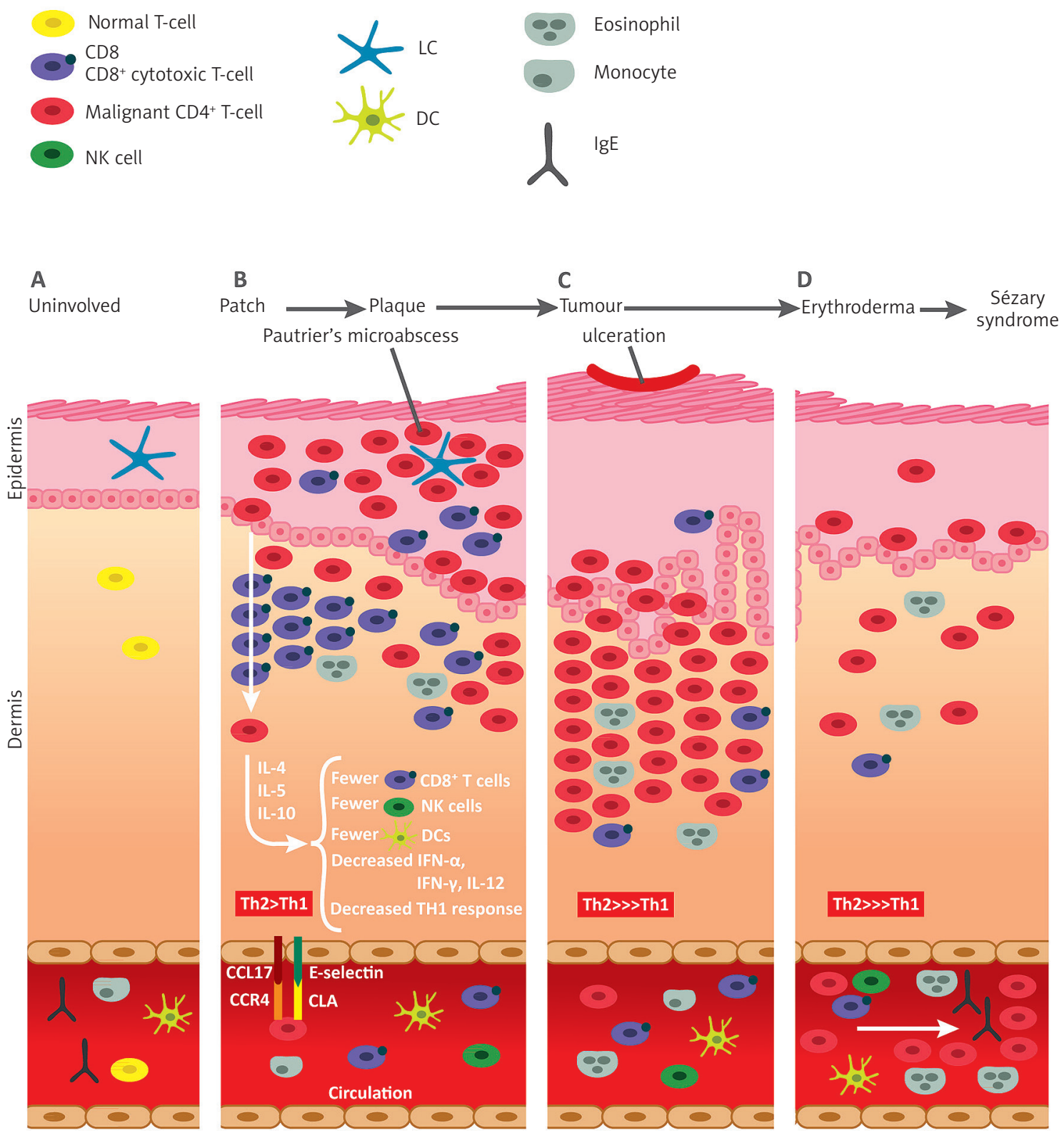

Figure 2. The skin microenvironment in MF progression. A - Normal skin, B - patch and plaque MF, C - tumour MF, D - erythrodermic MF and SS [3]

eral blood. They belong to a group of cytotoxic cells and have the capacity to destroy target cells without initial activation with specific antigens (which is necessary for cytotoxic T cells). Cytoplasmatic granules of NK cells contain phospholipids, proteoglycans and cytotoxic granzyme-type proteins and perforin. NK cells do not rearrange T-cell receptor (TCR) genes nor do they express surface CD3. Typical surface markers for NK cells are CD16 and CD56. The pathogenesis of the extra-nodal NK/T-cell nasal-type lymphoma involves deregulation of
TP53 and activation of MYC and NF- $\mathrm{B}$, likely induced by EBV LMP-1, which causes excessive cumulative activation of survivin, indisposes cancer cells to undergo apoptosis and thus provokes their unrestricted growth. Primary cutaneous marginal zone B cell lymphoma develops from mature $B$ lymphocytes, which proliferate in the course of an inflammatory process (related to Borrelia burgdorferi, the process parallels the relation between Helicobacter pylori infection and development of MALT in the stomach). 


\section{Risk factors}

The putative risk factors for MF/SS described recently include body mass index equal to or larger than $30 \mathrm{~kg} / \mathrm{m}^{2}$, cigarette smoking for 40 years or more, eczema, family history of multiple myeloma, and also professions such as crop and vegetable farmers, painters, woodworkers and carpenters were identified as increasing the risk of the disease. On the other hand, moderate leisure time physical activity seems to reduce the risk of MF/SS [4].

\section{Diagnostics, staging and criteria for treatment response}

In most of the cases, the initial diagnosis is put forward by a dermatologist in cooperation with a pathologist. Histopathological evaluation of the skin biopsy forms the basis for the diagnosis of the primary cutaneous lymphomas, which may be also sometimes diagnosed from a lymph node specimen or a biopsy specimen from another infiltrated organ. The skin biopsy specimen should not be taken from seborrheic areas, skin of the abdomen (if the abdomen is not the sole location of the lesions) nor from necrotic lesions, as these biopsies, statistically more often, present a non-specific histopathological picture, despite the correct technique of the examination. A biopsy of the whole lymph node is recommended in the case of lymphadenopathy to enable full evaluation of the structures and potential neoplastic infiltration. A thin or thick needle biopsy should never be attempted. Immunophenotyping of the abnormal cells should be pursued in every case, either by means of immunohistochemical evaluation of the biopsy specimen, or by flow cytometric analysis of the cell suspension (immunocytochemistry). Immunophenotyping enables assigning the lymphoma clone to the line of $T$ lymphocytes (CD2, CD3, CD4, CD5, CD7, CD8), B lymphocytes (CD19, CD20) or NK cells (CD16, CD56). In case of doubts, the basic staining can be extended to an expanded and more specific panel of monoclonal antibodies; cytogenetic and molecular testing can also be performed. Altogether these tests should enable identification of the histopathological subtype (WHO classification, Table 1) for each lymphoma case [5].

The diagnosis must be complemented with precise staging of the disease. Wallace rule of nines and/or rule of the palm can be used to evaluate the extent of skin lesions. The rule of nines assumes that the surface of the head as well as the surface of each arm comprises $9 \%$ of the body surface, the anterior torso or posterior torso comprises $18 \%$, each, of the body surface ( $9 \%$ is the anterior chest surface, $9 \%$ is the abdomen surface), the surface of each leg is $18 \%$ of the total and the genitalia/perineum constitute $1 \%$. The rule of the palm estimates that the surface of one's palm equals $1 \%$ of the total body surface. The above rules cannot be applied to infants, where the rule of fives is more adequate. The head, the anterior torso and posterior torso each constitutes $20 \%$ of the total body surface, with each extremity being 10\%. The Tu-
mour-Nodes-Metastasis-Blood (TNMB) classification is used for the precise staging of primary CLs (Tables 2 and 3) $[1,6]$. In the case of CTCL with lymph node and organ involvement and in CBCL, full staging should be performed according to the Ann Arbor criteria, as based on the clinical and histopathological evaluation alone the primary cutaneous cases cannot be distinguished from systemic lymphomas with secondary skin infiltration. Identification of the prognostic factors following the International Prognostic Index (IPI) (Table 2) is of pivotal importance for the further choice of the best treatment method as well as for the evaluation of the treatment results. Some distinct features of the diagnostic procedures for primary cutaneous lymphomas must be noted. In MF, which is the most common $\mathrm{CL}$, the radiological assessment of the chest and CT imaging of the abdominal cavity, head and neck, chest or pelvis are only performed in the case of extensive skin lesions and/or lymph node involvement and/or suspected infiltration of the internal organs. There is no need for imaging studies in IA-IIA stages of MF, neither is bone marrow assessment (aspiration or trephine biopsy) necessary. Peripheral blood morphology, on the other hand, should be examined in every patient, and in cases of erythroderma or extensive skin lesions, immunophenotyping of the peripheral blood cells should also be performed. The loss of CD26 antigen on more than $30 \%$ of peripheral CD4+ cells and/or loss of CD7 on more than $40 \%$ of the cells is tantamount to the peripheral blood involvement. The proportion of T4/ T8 greater than $10: 1$ has the same diagnostic significance. Cytological assessment of a peripheral blood smear with must be performed in search of Sézary cells. Finding more than 1000 Sézary cells in $1 \mu \mathrm{l}$ of blood suggests the involvement of the peripheral blood. Cutaneous T-cell lymphomas ( $40 \%$ of erythrodermic cases of MF, $15 \%$ of MF IA-IIA) may be accompanied by high concentration of total IgE in the blood (usually < 1000; the levels are not as high as in atopic dermatitis (AD), where lgE levels reach several thousand). Specific IgE radio-allergosorbent test (RAST) may prove helpful in the differential diagnosis, it is often positive in $\mathrm{AD}$ and only rarely in $\mathrm{CTCL}$. Blood lactate dehydrogenase levels (LDH) cannot serve as a differentiating factor between $\mathrm{CTCL}$ and AD. Some cases may require a molecular evaluation of the clonal rearrangement of T-cell receptors (TCR) or immunoglobulin (Ig) chains. It must be noted that identifying monoclonal rearrangement in a single biopsy does not prejudge the neoplastic origin of the lesion. For the neoplastic proliferation to be suspected in the skin biopsy, lymph nodes or peripheral blood, the clone should be identical in multiple locations. The similar rule applies to the evaluation of monoclonality in several skin specimens collected from one patient. The treatment response and monitoring of the disease can, in most cases of primary CL, be based on the skin examination according to the modified Severity Weighted Assessment Tool (mSWAT; Tables 4 and 5). The remission of the skin lesions may require a long time (2-3 months) despite adequate treatment. If no response 
Table 2. Classification of the skin lesions, nodal, extranodal and peripheral blood involvement in Mycosis Fungoides and the Sézary Syndrome according to the staging proposed in 2007 by the International Society for Cutaneous Lymphomas (ISCL) and the European Organization of Research and Treatment of Cancer (EORTC) and 2010 Tumour-Nodes-MetastasisBlood (TNMB) classification

\begin{tabular}{|c|c|c|}
\hline \multicolumn{3}{|r|}{ Skin lesions } \\
\hline \multirow[t]{3}{*}{$\mathrm{T} 1$} & & Limited patches ${ }^{*}$, papules and/or plaques ${ }^{* *}$ covering $<10 \%$ of the skin surface \\
\hline & T1a & Patch only $(<10 \%$ of the skin surface) \\
\hline & $\mathrm{T} 1 \mathrm{~b}$ & Plaque and patch (<10\% of the skin surface) \\
\hline \multirow[t]{3}{*}{$\mathrm{T} 2$} & & Patches, papules or plaques covering $\geq 10 \%$ of the skin surface \\
\hline & $\mathrm{T} 2 \mathrm{a}$ & Patch only ( $\geq 10 \%$ of the skin surface) \\
\hline & $\mathrm{T} 2 \mathrm{~b}$ & Plaque and patch ( $\geq 10 \%$ of the skin surface) \\
\hline $\mathrm{T} 3$ & & $\geq 1$ tumour $^{\star \star \star}(\geq 1 \mathrm{~cm}$ diameter $)$ \\
\hline T4 & & Confluence of erythema covering $\geq 80 \%$ of body surface area \\
\hline
\end{tabular}

${ }^{*}$ For skin, patch indicates any size skin lesion without any significant elevation or induration. Presence/absence of hypo- or hyperpigmentation, scale, crusting, and/or poikiloderma should be noted. ${ }^{* *}$ For skin, plaque indicates any size skin lesion that is elevated or indurated. Presence or absence of the same features as for patches should be noted. Histologic features such as folliculotropism or large-cell transformation (> 25\% large cells), CD30+ or CD30-, and clinical features, such as ulceration, are important to document. ${ }^{* * *}$ For skin, tumour indicates at least $1 \mathrm{~cm}$ diameter solid or nodular lesion with evidence of depth and/or vertical growth. Note the total number of lesions, total volume of lesions, largest size lesion, and the region of body involved. Also, note if histologic evidence of large cell transformation has occurred. Phenotyping for CD30 is encouraged.

\begin{tabular}{|c|c|}
\hline \multicolumn{2}{|r|}{ Node } \\
\hline NO & $\begin{array}{l}\text { No clinically abnormal peripheral lymph nodes (i.e. cervical, supraclavicular, epitrochlear, axillary, and inguinal); biopsy } \\
\text { not required }\end{array}$ \\
\hline N1 & Clinically abnormal* peripheral lymph nodes; histopathology Dutch grade 1 or NCI LN 0-2 \\
\hline N1a & Clone negative ${ }^{\star \star}$ \\
\hline $\mathrm{N} 1 \mathrm{a}$ & Clone positive ${ }^{\star *}$ \\
\hline N2 & Clinically abnormal* peripheral lymph nodes; histopathology Dutch grade 2 or NCI LN 3 \\
\hline $\mathrm{N} 2 \mathrm{a}$ & Clone negative ${ }^{\star \star}$ \\
\hline $\mathrm{N} 2 \mathrm{~b}$ & Clone positive** \\
\hline N3 & Clinically abnormal* peripheral lymph nodes; histopathology Dutch grades 3-4 or NCI LN4; clone positive or negative ${ }^{\star *}$ \\
\hline Nx & Clinically abnormal* peripheral lymph nodes; no histologic confirmation \\
\hline
\end{tabular}

*For node, abnormal peripheral lymph node(s) indicates any palpable peripheral node that on physical examination is firm, irregular, clustered, fixed, or $\geq 1.5 \mathrm{~cm}$ in diameter. Central nodes, which are not generally amenable to pathologic assessment, are not currently considered in the nodal classification. ${ }^{* *} \mathrm{~A}$ T-cell clone is defined by polymerase chain reaction or Southern blot analysis of the T-cell receptor (TCR) gene.

\begin{tabular}{lll}
\hline \multicolumn{2}{c}{ Histopathologic staging of lymph nodes } \\
\hline $\begin{array}{c}\text { ISCL/EORTC } \\
\text { (TNMB) }\end{array}$ & Dutch system & NCI-VA \\
\hline
\end{tabular}

ISCL/EORTC
(TNMB)

N1 Grade 1: dermatopathic lymphadenopathy (DL)
LNO: no atypical lymphocytes

LN1: occasional and isolated atypical lymphocytes (not arranged in clusters)

LN2: many atypical lymphocytes or in 3-6 cell clusters

LN3: aggregates of atypical lymphocytes; nodal architecture preserved of cerebriform nuclei $>7.5 \mu \mathrm{m}$ )

N3 Grade 3: partial effacement of LN architecture; many atypical cerebriform mononuclear cells (CMCs) Grade 4: complete effacement
LN4: partial/complete effacement of nodal architecture by atypical lymphocytes or frankly neoplastic cells 
Table 2. Cont.

\begin{tabular}{ll}
\hline M0 & No visceral organ involvement \\
\hline M1 & Visceral involvement (must have pathology confirmation* and the organ involved should be specified) \\
\hline${ }^{*}$ For viscera, spleen and liver may be diagnosed by imaging criteria. \\
\hline B0 & Absence of significant blood involvement: $\leq 5 \%$ of peripheral blood lymphocytes are atypical (Sézary) cells \\
\hline B0a & Clone negative* \\
\hline B0b & Clone positive* \\
\hline B1 & $\begin{array}{l}\text { Low blood-tumour burden: }>5 \% \text { of peripheral blood lymphocytes are atypical (Sézary) cells but does not meet the } \\
\text { criteria of B2 }\end{array}$ \\
\hline B1a & Clone negative* \\
\hline B1b & Clone positive* \\
\hline B2 & High blood-tumour burden: $\geq 1,000 / \mu l$ Sézary cells ${ }^{* *}$ with positive clone
\end{tabular}

${ }^{*} \mathrm{~A}$ T-cell clone is defined by polymerase chain reaction or Southern blot analysis of the T-cell receptor (TCR) gene; ** or blood, Sézary cells are defined as lymphocytes with hyper-convoluted cerebriform nuclei. If Sézary cells are not able to be used to determine tumour burden, then one of the following modified ISCL criteria may be used instead: 1) expanded CD4+ or CD3+ cells with CD4/CD8 ratio of $\geq 10$; and 2) expanded CD4+ cells with abnormal immunophenotype, including loss of CD7 or CD26.

MF-Mycosis fungoides, NCI - National Cancer Institute, NCI-VA - National Cancer Institute - Veterans Affairs, PCR-polymerase chain reaction, TCR - T-cell receptor.

is observed, but there is no progression, one should refrain from intensifying the treatment. A proportion of patients may stop treatment when in remission, until the relapse. For example PUVA (psoralen + UVA) therapy induces remission which may last for several years in 30-50\% of the patients. Some patients require à la longue supportive treatment, an example of which can be bexarotene and/or interferon $\alpha$ (IFN- $\alpha$ ) treatment in MF. In the case of the lymph node, peripheral blood, bone marrow and/or internal organ involvement, the response criteria and monitoring of the disease does not differ from standard recommendations for other neoplasms, which originate from mature T cells.

\section{Clinical presentation, differential diagnosis, treatment and prognosis}

Primary cutaneous lymphomas are characterised by different clinical course and prognosis compared to systemic lymphomas. Meticulous diagnosis and precise classification (Table 1) are essential for the selection of treatment options since particular types of lymphomas may differ significantly in grading, prognosis and treatment response. The effectiveness of therapy methods available at present is limited to reducing the symptoms. The ultimate cure is still unavailable. The choice of the treatment regimen should concentrate not only on the effectiveness but must also consider safety issues and quality of life.

\section{Primary cutaneous mature T and NK cell neoplasms}

\section{Subcutaneous panniculitis-like T cell lymphoma}

Subcutaneous panniculitis-like T-cell lymphoma (SPTCL) is a rare neoplasm seen in adults and children,
Table 3. International Society for Cutaneous Lymphoma (ISCL) and European Society of Research and Treatment of Cancer (EORTC) Anatomic Stage and Prognostic Groups of Mycosis Fungoides and the Sézary Syndrome

\begin{tabular}{|c|c|c|c|c|}
\hline Stage & $\mathrm{T}$ & $\mathrm{N}$ & $M$ & $\begin{array}{c}\text { Peripheral blood } \\
\text { involvement }\end{array}$ \\
\hline \multicolumn{5}{|l|}{ I: } \\
\hline IA & 1 & 0 & 0 & 0,1 \\
\hline IB & 2 & 0 & 0 & 0,1 \\
\hline \multicolumn{5}{|l|}{ II: } \\
\hline$\| A$ & 1,2 & $0-2$ & 0 & 0,1 \\
\hline IIB & 3 & $0-2$ & & 0,1 \\
\hline III: & 4 & $0-2$ & 0 & 0,1 \\
\hline IIIA & 4 & $0-2$ & 0 & 0 \\
\hline IIIB & 4 & $0-2$ & 0 & 1 \\
\hline \multicolumn{5}{|l|}{ IV: } \\
\hline IVA1 & $1-4$ & $0-2$ & 0 & 2 \\
\hline IVA2 & $1-4$ & 3 & 0 & $0-2$ \\
\hline IVB & $1-4$ & $0-3$ & 1 & $0-2$ \\
\hline
\end{tabular}

which affects both sexes with a comparable incidence. The clinical presentation includes solitary or multiple tumours and/or infiltrates, located within the subcutaneous tissue of the extremities or trunk, with features simulating panniculitis. These lesions are often accompanied by fever, fatigue, body weight loss, peripheral blood cytopenia and increased activity of the liver en- 
Table 4. Modified Severity Weighted Assessment Tool (mSWAT) and evaluation of the progression/remission of the skin involvement (Rule of the Palm: the surface area of patient's palm with fingers equals $1 \%$ of the body surface)

\begin{tabular}{|c|c|c|c|c|}
\hline \multirow[t]{2}{*}{ Body region } & \multirow{2}{*}{$\begin{array}{c}\% \mathrm{BSA} \\
\text { in body region }\end{array}$} & \multicolumn{3}{|c|}{ Assessment of involvement in patient's skin } \\
\hline & & Patch* & Plaque ${ }^{\star \star}$ & Tumour*** \\
\hline Head & 7 & & & \\
\hline Neck & 2 & & & \\
\hline Anterior trunk & 13 & & & \\
\hline Arms & 8 & & & \\
\hline Forearms & 6 & & & \\
\hline Hands & 5 & & & \\
\hline Posterior trunk & 13 & & & \\
\hline Buttocks & 5 & & & \\
\hline Thighs & 19 & & & \\
\hline Legs & 14 & & & \\
\hline Feet & 7 & & & \\
\hline Groin & 1 & & & \\
\hline Subtotal of lesions (\%BSA) & 100 & A & B & C \\
\hline Weighting factor & ND & $\times 1$ & $\times 2$ & $\times 4$ \\
\hline Subtotal lesion $(\% \mathrm{BSA}) \times$ weighting factor & ND & $A \times 1$ & $B \times 2$ & $C \times 4$ \\
\hline
\end{tabular}

${ }^{*}$ For skin, patch indicates any size lesion without any induration or significant elevation above the surrounding uninvolved skin. Poikiloderma should be noted. ${ }^{* *}$ For skin, plaque indicates any size lesion that is elevated or indurated; Crusting, ulceration, or poikiloderma may be present. ${ }^{* * *}$ For skin, tumour indicates any solid or nodular lesion $\geq 1 \mathrm{~cm}$ in diameter with evidence of deep infiltration in the skin and/or vertical growth. For erythroderma, only patch and plaque columns should be considered.

mSWAT score equals the sum total of each column line: $m S W A T=[(A \times 1)+(B \times 2)+(C \times 4)] ; \% B S A-\%$ body surface area; ND - not done.

Table 5. Modified Severity Weighted Assessment Tool (mSWAT) evaluation of the response in skin

\begin{tabular}{ll}
\hline Response & Definition \\
\hline Complete response (CR) & $100 \%$ clearance of skin lesions* \\
\hline Partial response (PR) & $\begin{array}{l}50-99 \% \text { clearance of skin disease from baseline without new tumours (T3) in patients with T1, T2 or T4 } \\
\text { (only skin disease) }\end{array}$ \\
\hline Stable disease (SD) & $<25 \%$ increase to < 50\% clearance in skin disease from baseline without new tumours (T3) in patients \\
& with T1, T2, or T4 (only skin disease) \\
\hline Progressive disease (PD)** & $\begin{array}{l}\text { (only skin disease) or } \\
\text { Loss of response: in those with complete or partial response, increase of skin score of greater than the } \\
\text { sum of nadir plus } 50 \% \text { baseline score }\end{array}$ \\
\hline Relapse & Any disease recurrence in those with complete response \\
\hline
\end{tabular}

${ }^{*}$ A biopsy of normal appearing skin is unnecessary to assign a complete response. However, a skin biopsy should be performed of a representative area of the skin if there is any question of residual disease (persistent erythema or pigmentary change) where otherwise a complete response would exist. If histologic features are suspicious or suggestive of mycosis fungoides/Sézary syndrome, the response should be considered a partial response (PR) only. ${ }^{* * W h i c h ~ e v e r ~}$ criterion occurs first.

zymes in the blood. Subcutaneous panniculitis-like T-cell lymphoma can be complicated be the haemophagocytic syndrome (HPS), which is usually related to a fast progression of the disease (approx. 15\% of the patients). The infiltration is limited to the subcutaneous tissue, while dermis and epidermis are spared. The histopathological examination shows infiltration predominantly with lymphoma cells presenting with the $\alpha \beta($ CD3+CD4-CD8+) phenotype. There is no standard therapeutic approach. Glucocorticosteroids (prednisone 30-50 mg/day) are usually used, and can be augmented with small doses of methotrexate (MTX) in resistant cases. SPTCL with HPS necessitates implementation of the treatment strategies for aggressive mature T cell lymphomas, such as chemotherapy (CHOP, cyclophosphamide, doxorubicin, vincristine, prednisone) and/or radiotherapy. This type of lym- 
phoma has a good prognosis: 5-year survival rate reaches $91 \%$ in patients without HPS and $46 \%$ if HPS is present. For cases with CHOP-resistant HPS, the following treatments are employed: cladribine, DHAP (dexamethasone, cytarabine, cisplatin), ESHAP (etoposide, methylprednisolone, cytarabine, cisplatin), FLAG (fludarabine, cytarabine, GMCSF), mini-BEAM (carmustine, etoposide, cytarabine, and prednisone, procarbazine and bleomycin) and transplantation of hematopoietic stem cells [7-13].

\section{Mycosis fungoides [5]}

Mycosis fungoides (MF) is the most common primary cutaneous lymphoma, which affects mainly adults, with a slight predominance of males. The median age at diagnosis is 55-60 years. The skin lesions appear in three stages, with pruritus present at every stage of the disease. The initial period (MF I, premycotic; stadium praemycoticum, Figure 3) presents with erythematous and erythematous-scaly or eczema-type lesions, which are located mainly at the non-sun-exposed areas of the skin. During the infiltration period, (MF IB-IIA, stadium infiltrativum, Figure 4) flat, round, oval or ring or archlike infiltrations predominate, both within the previously erythematous areas and within the unchanged skin. The lesions can generalise and over $80 \%$ of the skin surface may be affected (MF III, erythroderma). The tumorous stage (stadium tumeriforme, Figures 5 and 6 ) is marked by the presence of livid-red tumours with the tendency to ulcerate. The tumours arise from infiltrations or de novo, from the uninvolved skin. All the above-mentioned lesions may coincide. Lymphomatous infiltrations of the lymph nodes and of the visceral organs may be present in advanced stages of the disease. Histopathology of MF is different at particular stages of the disease. Histology of the premycotic stage is nonspecific and predominantly mimics chronic inflammation. Typical lesions are seen in stadium infiltrativum with infiltrates containing smalland middle-size T lymphocytes with hyperchromatic, irregular nuclei (nucleus cerebriformis) which reside in the sub-epidermal layer and partially infiltrate the epidermis (epidermotropism). Characteristic features of the infiltrative phase are Pautier's microabscesses, i.e. the intraepithelial, thick infiltrates of atypical T lymphocytes. The lymphoma cells present with a phenotype of mature Thelper lymphocytes CD3+, CD4+, CD45RO+, CD8-, MF with CD4-, CD8+ phenotype is rather rare. The tumorous stage (stadium tumeriforme) is marked by infiltrates that are thicker and involve deep layers of the dermis or even the subcutaneous tissue. Epidermotropism may be present at any stage of MF. Late stages may present with $T$ lymphocytes of altered antigenic composition pan- $T$ antigens disappear and an expression of CD30+ is noted. Thirty one variants of MF have been described. The most common, apart from the classical form, include folliculotropic mycosis fungoides, pagetoid reticulosis and granulomatous slack skin. Early stages of

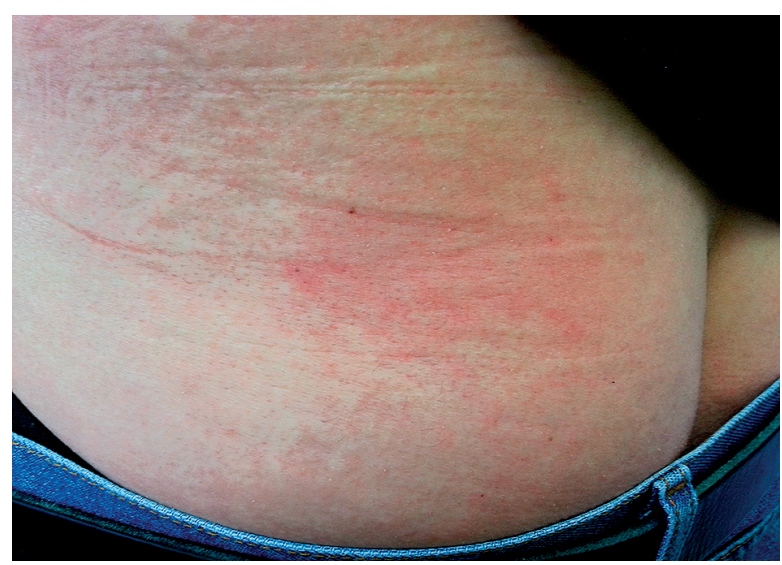

Figure 3. Premycotic stage of mycosis fungoides

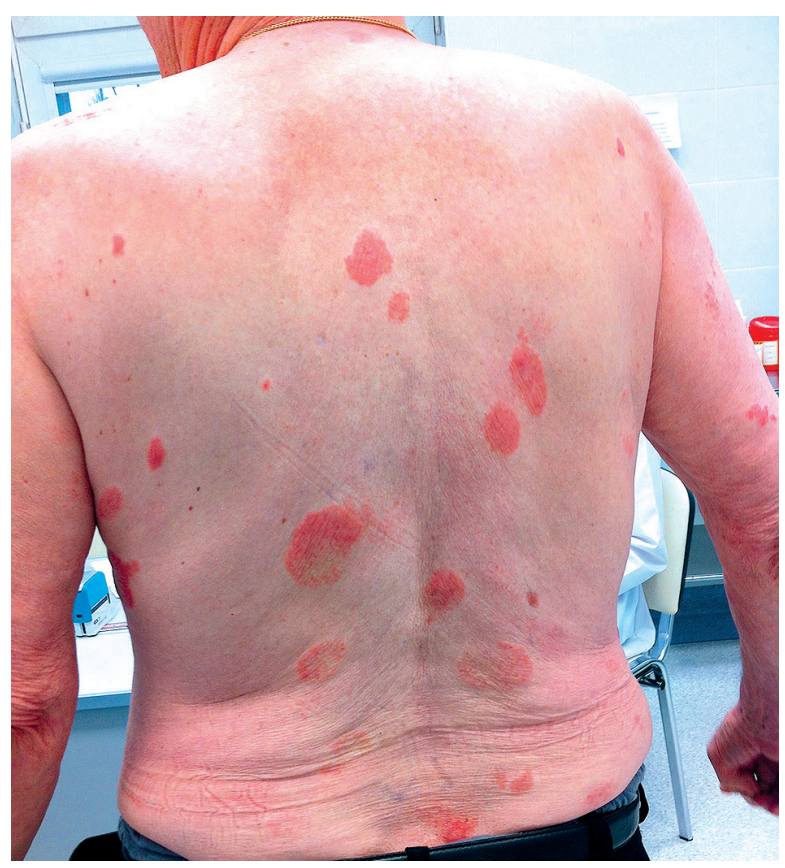

Figure 4. Plaques in mycosis fungoides

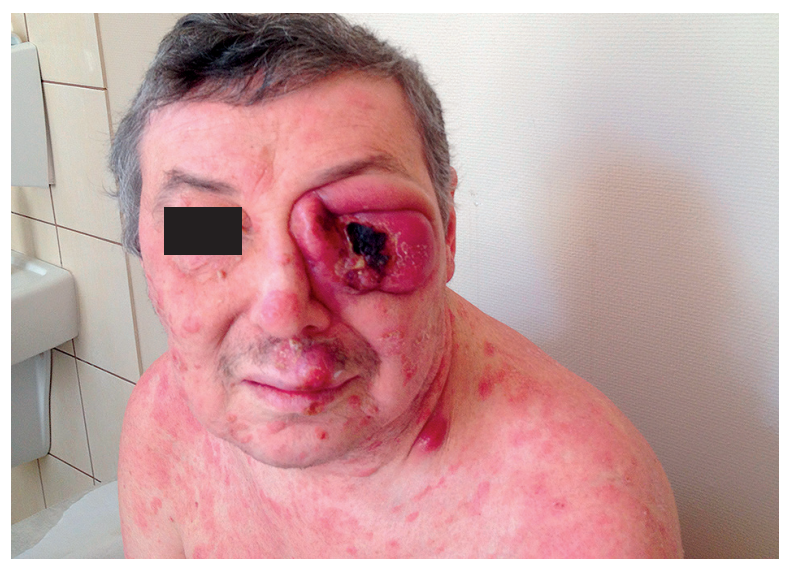

Figure 5. Mycosis fungoides - tumoral stage 


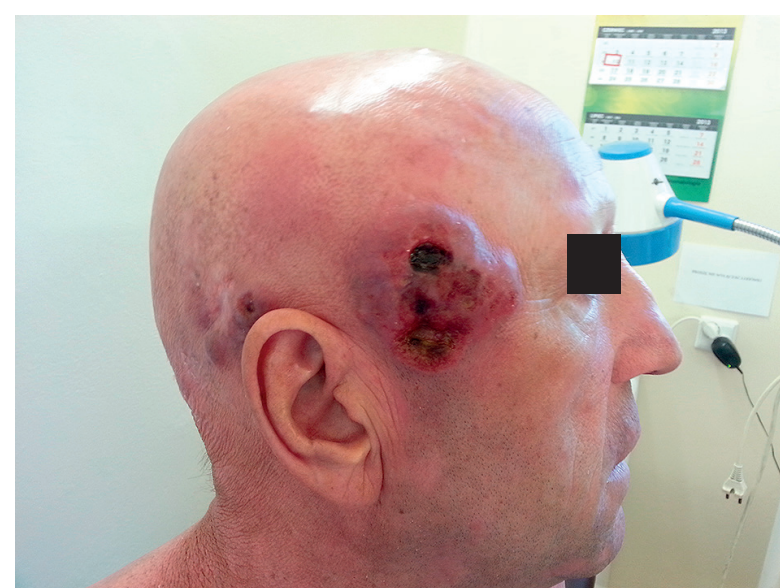

Figure 6. Tumour in mycosis fungoides

folliculotropic MF may be resistant to topical treatment, such as mechlorethamine and PUVA, due to the depth of the infiltrate. Phototherapy should be used only in combination with interferon- $\alpha$ (IFN- $\alpha$ ) and retinoids or rexinoids. Total skin electron beam (TSEB) therapy is the recommended treatment with adjuvant radiotherapy for persistent tumours. Pagetoid reticulosis includes a limited type formerly named - Woringer-Kolopp disease. Topical steroids and mechlorethamine are the treatment of choice. Granulomatous slack skin is a rare subtype of MF, characterized by localized areas of bulky folding of the skin, with a predilection for the axillae and groins, with a granulomatous infiltrate consisting of clonal T cells. Radiotherapy is the treatment of choice as rapid relapses were described after surgical removal. The clinical course of the classical variant of MF is usually mild and chronic, but the ultimate treatment is rarely feasible. Clinical evaluation of the therapy response is sufficient for IA grade (withdrawal of the erythema), but the advanced stages require histopathological evaluation to assess the recession of the skin lesions. For early stages of the disease (stage IA-IIA), the least toxic therapy is recommended, but the treatment should ensure the regression of the lesions. The first-line therapy is usually supervised by dermatologists. In the case of single patchy lesions, I class topical glucocorticosteroids can be applied, such as $0.05 \%$ betamethasone dipropionate or $0.1 \%$ mometasone furoate. Topical treatment may also include cytostatics, like mechlorethamine (nitrogen mustard) in $10-20 \mathrm{mg} / \mathrm{ml}$ solutions or $0.02 \%$ gel or ointment once daily (mSWAT response $46.9 \%$ vs. $46.2 \%$ ) or carmustine (BCNU) in 20-40\% ointment or 10 mg/60 ml 95\% alcohol solution once a day [14-16]. PUVA, UVB and UVA therapy is recommended in patchy-plaques which involve more than $30 \%$ of the skin surface [17-19].

PUVA therapy comprises oral administration of 8-metoxypsoralen (8-MOP) at a dose of $0.60 .8 \mathrm{mg} / \mathrm{kg}$ body weight or 5-metoxypsoralen (5-MOP) $1.2-1.4 \mathrm{mg} / \mathrm{kg}$
1 to $2 \mathrm{~h}$ before $320-400 \mathrm{~nm}$ UVA irradiation. PUVA is applied 2-3 times a week till the skin lesions withdraw (usually 3-4 months). Complete remissions (CR) are achieved in $58-83 \%$ of the patients, and partial remissions (PR) in 95\%. The average duration of the therapy is 43 months. Subsequently, when a response is noted, PUVA is administered for the next 2-3 months with a lower frequency. The most common side effects of PUVA treatment include nausea due to psoralens and photosensitivity. Solar keratosis, or better say PUVA keratosis, may develop with long-term therapy. The patchy stage of MF may be treated with wide (300-320 nm) or narrow spectrum (311 nm) UVB therapy, which is better tolerated than PUVA, but as it is less effective, should not be recommended in stadium infiltrativum [17-19]. The efficacy of the PUVA therapy can be boosted by an addition (second-line therapy) of retinoids (acitretin, isotretinoin), rexinoid (bexarotene) or IFN- $\alpha 3-5 \mathrm{MU}$ 3 times a week [20-23]. Oral bexarotene $\left(300 \mathrm{mg} / \mathrm{m}^{2}\right)$ is useful in patients with MF resistant to treatment. Response is expected in 2-4 months. The lipid profile and thyroid hormone function should be monitored during treatment with bexarotene [24-29].

In cases for which PUVA therapy is contraindicated, TSEB therapy is an option [30]. The most common dose (30-36 Gy) used in TSEB allows for CR in 60-90\% of T2-T4 patients and provides 5 -year relapse-free survival in 10-25\% of patients with stage IB-III. Smaller doses (10 Gy in weekly 1 Gy sessions) provide $90 \%$ of patients with response, including CR and very good partial remission (VGPR) in $70 \%$ ( $<1 \%$ of the skin surface involved with patchy or plaque lesions). The average response duration is 5.2 months (83-469 days). Smaller doses were burdened with lower intensity of the side effect and allow for repeated treatment in the case of relapse/progression [30].

X-ray radiotherapy should be considered for tumorous lesions. Diversified strategies can be applied, depending on the extent and depth of the infiltration, namely conventional $X$ radiation, so called orthovoltage therapy with low energy (80-140 kVp) or slightly higher (200-280 kVp), $\gamma$-radiation Co-60 (1.25 MeV) and electron beams (4-20 MeV), which penetrate the superficial and deeper layers of the skin, subcutaneous tissue as well as superficially located lymph nodes, while photon beams (4-20 MeV) may be used for irradiation of the deeper located neoplastic lesions. Cutaneous lymphomas show very good response to radiotherapy (90-95\% CR). The higher the total dose, the lower risk of relapse. The dose of 10 Gy gives $40 \%$ risk of relapse, 20 Gy - 32\%, 2025 Gy - 20\%, while doses exceeding 30 Gy warrant almost $0 \%$ risk of relapse. Most relapses occur within the first year after irradiation (80\%), and almost all take place before the end of the second year. Local skin lesions can be adequately controlled with total doses of 30-40 Gy (fraction dose $2 \mathrm{~Gy}$, with total treatment duration of 3-4 weeks). Solitary and limited MF lesions 
show excellent response to limited field electron beam irradiation with a total dose of $30 \mathrm{~Gy}$. The 10-year overall survival rate (OS) reaches almost 100\% and 10-year relapse-free survival is achieved in $80 \%$ of the patients. Selected clinical scenarios of advanced MF may require palliative low-dose total body irradiation with high energy X-ray photons. It was demonstrated that chemotherapy does not prolong OS in IIB-IVB patients, and thus INF- $\alpha$ and bexarotene are recommended as the first-line therapy, with the same dosing as for less advanced stages. Clinical trials are another therapeutic option for MF patients, before the systemic chemotherapy is started.

The second-line therapy for MF may also include oral MTX at 20-75 mg a week (in three doses every $12 \mathrm{~h}$ every 7 days), which can be combined with glucocorticosteroids, PUVA and IFN- $\alpha[31,32]$. Treatment for IIB-III stages is usually started with PUVA therapy, combined with IFN- $\alpha$ or MTX [33]. As chemotherapy does not prolong survival in advanced MF, drugs with another mechanism of action are recommended, such as bexarotene, IFN- $\alpha$ or denileukin diftitox 9 or $18 \mu \mathrm{g} / \mathrm{kg} /$ day for five consecutive days every 3 weeks (8 cycles) (phase III clinical trial ORR 30\%, 10\% CR, avg. OS 6-9 months with a range from 2.7 to 46.1 months). Histone deacetylase inhibitors (HDACi) were recently proven effective in MF. Two HDACi - vorinostat and depsipeptide have already been approved by the US Food and Drug Administration (FDA) for the treatment of MF. Vorinostat was reported to provide ORR of $27.9 \%$, pruritus reduction in $50 \%$ of the patients and time to disease progression of 4.9 months in phase II and IIB clinical trials. Depsipeptide, at a dose of $14 \mathrm{mg} / \mathrm{m}^{2}$, given on day $1,8,15$ in cycles repeated every 28 days, gave $35 \%$ ORR and average time of the response of 13.7 months. Moreover, panobinostat (20 mg, 3 times a week) given to patients with a history of at least two systemic treatments, including, or not, bexarotene, decreased mSWAT score in $74.1 \%$ of the patients with the ORR of $17.3 \%$ (phase IIb clinical trial, ORR 15.2\% and $20 \%$, respectively, and the median survival of 4.2 and 3.7 months). In the light of recent reports, the use of IFN- $\gamma$ requires further studies [34-42]. If the treatment described above proves ineffective, or is not available, clinical trial enrolment is recommended, before a systemic chemotherapy is initiated. Classical chemotherapy should be the last option [43]. Patients with smouldering progression can start chemotherapy with oral chlorambucil at $4 \mathrm{mg} /$ day or etoposide at $50 \mathrm{mg} /$ day. The timing should be adapted to the individual tolerance and efficacy. For patients with rapid MF progression, monotherapy starting with gemcitabine (6 cycles $1200 \mathrm{mg} / \mathrm{m}^{2}$ i.v. every week) or liposomal doxorubicin $\left(40 \mathrm{mg} / \mathrm{m}^{2}\right.$ i.v. once a month). Liposomal doxorubicin allows for $56 \%$ response rate, still with only 5 -month disease-free survival. Pegylated liposomal doxorubicin, at $20 \mathrm{mg} / \mathrm{m}^{2}$ i.v. once a month, gives CR and PR in $88 \%$ of the patients. It is worth noting that a combination of gemcitabine with bexarotene does not provide any therapeutic advantage over gemcitabine in monotherapy [2]. Addition of bexarotene to liposomal doxorubicin treatment $\left(20 \mathrm{mg} / \mathrm{m}^{2}\right.$ i.v. every 2 weeks for 16 weeks) does not prolong the remission neither does it improve the effectiveness, as demonstrated in phase II clinical trial. Polychemotherapy should be used only as the last therapeutic option, only in patients resistant to the previous treatment and those with advanced lymphadenopathy and/or visceral involvement (IVA-IVB) in need of rapid reduction of the tumour burden. Polychemotherapy regimens, such as $\mathrm{CHOP}, \mathrm{EPOCH}$ (etoposide, vincristine, doxorubicin, cyclophosphamide, prednisone), ESHAP (etoposide, cisplatin, high-dose cytosine arabinoside, methylprednisolone) and cladribine/ fludarabine in combination with cyclophosphamide (CC scheme/FC), allows to obtain a transient response (often lasting only for a few weeks) [1, 2]. It should be stressed that purine analogues (cladribine, fludarabine), used in polychemotherapy regimens in $\mathrm{CTCL}$, are related to a higher mortality rate due to infections. Oral antibiotic prophylaxis is recommended for necrotic lesions within tumours. Topical treatment of the ulcers should only include antiseptics, such as octenidine dihydrochloride in solution. Topical antibiotics should be avoided because they stimulate rapid progression of resistance.

For young patients, diagnosed with III-IV grade MF and still in good general condition, but with a history of ineffective treatment with IFN- $\alpha$, bexarotene, histone deacetylase inhibitors or denileukin diftitox, should be considered for allogenic stem cell transplantation (allo$\mathrm{HSCT}$ ), preferred over initiation of the cytostatic treatment. Allo-HSCT, with standard conditioning, results in complete and long-lasting remissions, however at the cost of the infection risk and peritransplant complications. Allo-HSC with reduced-intensity conditioning (RIC) gives a lower peritransplant mortality rate, but the duration of the response may be shortened [1].

\section{Other investigational therapies}

Lenalidomide, a thalidomide analogue that has been approved by the US Food and Drug Administration for the treatment of myelodysplastic syndrome and relapsed/refractory multiple myeloma and mantle cell lymphoma, enhances T and NK cells mediated killing and also increases Th1-cytokine production [44]. Side effects include cytopenias, temporary flares of skin disease and circulating Sézary cells. Querfeld et al. in phase II trial of 32 patients with advanced CTCL showed an ORR of $29 \%$ [45].

Toll-like receptor agonists are another method of therapy for CTCL. They mimic bacterial antigens and stimulate the innate immune response [46, 47]. Zanolimumab is a monoclonal anti-CD4-antibody, interrupting the T-cell activation, thus leading to a reduction in the T-cell number. Its efficacy in MF has been shown in two separate phase II studies, a phase III study has not been 
completed. A 56\% ORR was reported in phase II study, side effects included infections and dermatitis [48].

The prognosis in MF depends on the phase of the disease, its type, extent of the skin lesions and lymph node and/or internal organ involvement. Patients with limited erythematous-infiltrative stage of the disease, involving less than $10 \%$ of the skin surface have a 10 -year survival rate of $97-98 \%$, and patients with the disease involving more than $10 \%$ of the skin surface have a 10 -year survival rate of 83 . The rates drop to $42 \%$ in the tumorous stage and $20 \%$ in the MF with organ involvement [49].

\section{Lymphomatoid papulosis}

Lymphomatoid papulosis (LyP) has a long, recurrent course. It presents with papules in the skin of the trunk and the extremities. The papules appear scaly and typically develop superficial necrosis with time (Figure 7), they also tend to heal spontaneously (in 3-12 weeks). Lymphomatoid papulosis mainly affects adults, with a slight predominance of males. The median age at diag nosis is 45 years. Histologically, lymphomatoid papulosis is divided into the following 4 subtypes [50]:

- type A characterized by large CD30+ atypical cells intermingled with a prominent inflammatory infiltrate consisting of histiocytes, small lymphocytes, granulocytes and eosinophils;

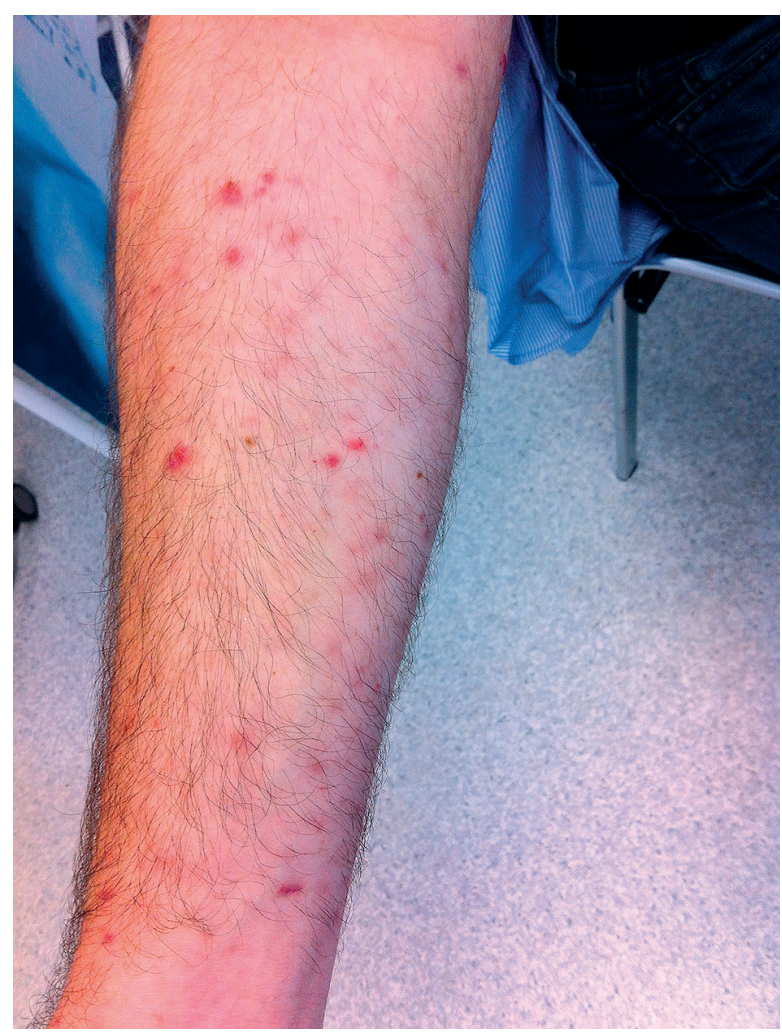

Figure 7. Lymphomatoid papulosis
- type B characterized by epidermotropism and infiltration with smaller atypical cells with hyperchromatic cerebriform nuclei resembling atypical lymphocytes in $M F$, and of antigen composition of C-ALCL;

- type C characterized by sheets of CD30+ anaplastic large lymphocytes;

- type D characterised by infiltrates similar to those in CD8+ aggressive epidermotropic lymphoma or/and resembling pagetoid reticulosis (CD8+ CD30+, sometimes CD4+, CD56+).

Patients with mild skin lesions may require no treatment. Small doses of MTX (5-20 mg once a week) provide disease control in those who must be treated. Folic acid supplementation is recommended at a dose of 5$10 \mathrm{mg}$ once a week on a MTX-free day, to counteract the toxic antimetabolic effect of MTX. A good effect was reported with PUVA which may be combined with IFN- $\alpha$, retinoids or rexinoids. Resistant single lesions of more than $2 \mathrm{~cm}$ in diameter may be surgically removed or treated with radiotherapy (the irradiation options are the same as described for MF). Despite complete cure being unavailable, general prognosis for LyP is good. Lymphoproliferative disorders, most often ALF, MF, HL or non-Hodgkin lymphoma ( $\mathrm{nHL}$ ) may coincide with LyP in 30-50\% of the patients. This observation necessitates regular check-ups in LyP patients, although the optimal frequency of the imaging studies is not determined and should be adjusted to the general condition of the patient and signs and symptoms [7, 51, 52].

\section{Primary cutaneous anaplastic large cell lymphoma}

Primary cutaneous anaplastic large cell lymphoma (C-ALCL) affects mainly male adults. Clinical presentation includes solitary (80\%) or numerous (20\%) tumours, $1-10 \mathrm{~cm}$ in diameter. Solitary tumours resolve spontaneously in $1 / 3$ of the cases. Secondary involvement of the local lymph nodes is present in every tenth patient, in that case a secondary skin involvement in systemic anaplastic large cell lymphoma (ALCL), Hodgkin lymphoma (HL) or MF CD30+ must be ruled out. Histopathologically, C-ALCL presents with diffuse infiltration of the dermis with CD4+ lymphocytes, with loss of one or more of pan-T-cell markers such as CD2, CD3, and CD5. For the diagnosis of C-ALCL, at least 75 percent of the large cells should express CD30. Neoplastic cells express the cutaneous lymphocyte antigen (CLA) and usually lack the epithelial membrane antigen (EMA) and anaplastic lymphoma kinase (ALK). Methotrexate (MTX), at a weekly dose of $30 \mathrm{mg}$ (in three doses every $12 \mathrm{~h}$ every 7 days), is used. After the remission is achieved, the treatment can be gradually discontinued. Usually the relapses are not expected. Single tumours can be surgically removed or treated with radiotherapy 30-46 Gy (in 2 Gy fractions) covering $2-3 \mathrm{~cm}$ margin of uninvolved skin surrounding the lesion. Complete remissions are achieved in 
$95 \%$ of the patients. Spontaneous or partial remissions of the tumours are seen in $44 \%$ of the cases (after 1 week 6 months from the onset). In the rare instances of secondary visceral involvement, chemotherapy is recommended (CHOP, cyclophosphamide, doxorubicin, vincristine, prednisolone). IFN- $\alpha$, bexarotene or monoclonal anti-CD30 antibodies (brentuximab vedotin) may be considered (see Mature T and NK cell neoplasms). Despite potentially disturbing histopathological presentation with pronounced cellular atypia, C-ALCL usually carries a good prognosis, with an over $90 \%$ rate of 10 -year survival [7, 51-53].

\section{Primary cutaneous CD-4-positive small/medium T-cell lymphoma}

Primary cutaneous CD-4-positive small/medium T-cell lymphoma presents with single plaques or tumours, which are found on the face, neck or upper half of the body. The diagnosis is made only when erythematous patches and plaques, typical of MF, are absent (at present or in the past). Histopathologically this lymphoma presents with packed, diffuse infiltration, containing small and medium T lymphocytes with CD3+, CD4+, CD8 - and CD30- phenotype and a significant proportion of B lymphocytes and histiocytes (see Classification and diagnostic criteria of the lymphatic neoplasms; Figure 1). Pleomorphic, large T cells should constitute no more than $30 \%$. Neoplastic infiltration usually penetrates the deeper layers of the skin or even the subcutaneous tissue, with possible focal epidermotropism. The clinical course of this neoplasm is benign. Surgical removal and radiotherapy are treatment options for solitary tumours or plaques. Cyclophosphamide or IFN- $\alpha$ may be used in generalised skin involvement. The prognosis is good with a 5-year survival rate of 60-80\% [7, 54-57].

\section{Sézary syndrome}

Sézary syndrome (SS) is characterized by a triad of diffuse erythroderma, generalized lymphadenopathy, and malignant T cells with cerebriform nuclei, the so-called Sézary cells, present in the skin, lymph nodes and circulating in the peripheral blood. The International Society for Cutaneous Lymphoma (ISCL) proposed that at least one of the following criteria must be fulfilled for the diagnosis of SS:

- absolute Sézary cell count in the peripheral blood of at least 1,000 cells $/ \mathrm{mm}^{3}$;

- abnormal antigens are present at the surface of T-lymphocytes, i.e. increase in CD4+ population with an increased CD4/CD8 ratio to more than 10 and/or loss of one or all of pan-T antigens (CD2, CD3, CD4, CD5);

- evidence of a circulating T-cell clone detected by molecular or cytogenetic methods.

De novo SS must be distinguished from a disease with secondary erythroderma in patients with previous typical MF lesions (milder clinical course of MFIII com- pared to SS). SS demonstrates histological features similar to those of MF, with less epidermotropism $[1,7,58]$.

Sézary syndrome is a rare disease and affects mainly adult males. The median age at diagnosis is 63 years. Initial skin lesions are not characteristic, eczema-like or similar to chronic inflammatory lesions. Subsequently erythroderma develops. The skin is thicker and erythematous with marked exfoliation. Erythroderma is accompanied by intense pruritus. Other SS symptoms include alopecia, onychodystrophy, hyperkeratosis of the palms and soles and generalised lymphadenopathy. Histopathological presentation resembles that of MF, but the neoplastic infiltration is more monomorphic and may show no epidermotropism. Neoplastic T cells are mostly CD3+, CD4+ and CD8 - with a lost expression of CD7 and CD26 on the circulating Sézary cells. Extracorporeal photopheresis (ECP) is the treatment of choice in SS, which is often combined with bexarotene or IFN- $\alpha$. ECP gives a $30-80 \%$ response $(C R+P R)$ rate, with CR achieved in $14-25 \%$ of the patients. As with advanced MF, it is recommended to start systemic treatment with IFN- $\alpha$, bexarotene, romidepsin or denileukin diftitox. The general recommendations regarding the implementation of systemic chemotherapy are similar to MF. Patients with a slow progressing disease may start the treatment with MTX 15-25 mg once a week or chlorambucil 2-4 mg/day. Methotrexate at low doses is well tolerated and can be administered for several years. Patients with more rapid progression are recommended to start monochemotherapy with gemcitabine or liposomal doxorubicin (as for MF). Younger patients should be considered for allo-HSCT, preferable to aggressive chemotherapy, as the median of the expected survival is short. Prognosis in SS is unfavourable, with median survival of 2-4 years. Patients die due to an opportunistic infection facilitated by a decreased immune response which is an element of the disease $[1,7]$.

\section{Primary cutaneous $\gamma \delta$ T-cell lymphoma}

Primary cutaneous $\gamma \delta$ T-cell lymphoma (PCGD-TCL) is characterised by disseminated infiltrations and/or nodules with ulcerations or tumours which are found mainly on the extremities. Involvement of the mucous membranes or other extranodular sites is quite common, but the lymph nodes, spleen or bone marrow are usually spared. Cells with a cytotoxic phenotype (i.e. CD2+, CD3+, CD5-, CD7+/-, CD56+, bF1-, g/d+ and CD4- and CD8-) are found in the epidermis, dermis and subcutaneous tissue in the histopatological evaluation. All three layers are often infiltrated at the same time. The clinical course is very aggressive. There is no optimal treatment. Most centres adapt polychemotherapy (CHOP or other) in combination with radiotherapy. Young patients in a good general condition should be considered for allo-HSCT. Median survival is only 15 months [7, 8, 59-62]. 


\section{Primary cutaneous aggressive epidermotropic CD8+ T-cell lymphoma}

Primary cutaneous aggressive epidermotropic CD8+ T-cell lymphoma (AECTCL) manifests with circumscribed or diffuse skin papules, nodules and tumours, often with central necrosis. Lymphomatous infiltrates may also be found in the lungs, testes, central nervous system (CNS) and oral mucosa, but the lymph nodes are usually of normal size. The neoplastic infiltrate is characterised by the presence of epidermotropic CD3+, CD8+, bF1+, granzyme B+, perforin+, TIA-1+, CD45RA+, CD45RO-, CD2-, CD4-, CD5-, CD7+/- T lymphocytes. AECTCL must be differentiated with so called indolent lymphoid CD8+ proliferation of the ear (with possible nose location), which is a lesion with histopathological findings typical of an aggressive lymphoma (CD3+, CD4-, CD8+, TIA-1+, granzyme B-, CD30-) but a very benign clinical course. AECTCL has an aggressive clinical course. There is no optimal treatment. Most centres adapt polychemotherapy (CHOP or other) in combination with radiotherapy. Young patients in a good general condition should be considered for allo-HSCT. Median survival is 32 months [7, 8, 59-61, 63, 64].

\section{Extra-nodal NK/T-cell lymphoma, nasal-type}

Extranodal NK/T-cell lymphoma, nasal type (ENKTCL) was described together with mature T and NK cell neoplasms (see appropriate section). It should be noted that skin is the second most frequent extranodular location of this type of lymphoma. The most common extranodular location is the nose cavity and pharynx. Skin can be involved primarily or secondarily. Multiple infiltrates and tumours are usually found in the skin of the trunk and extremities or a solitary tumour within the nasopharynx which tends to ulcerate and destroy the surrounding tissues. Systemic symptoms, such as fever, fatigue and body weight loss accompany the skin infiltrates. Symptoms of the haemophagocytic syndrome may also occur. Histopathology reveals NK/T cell infiltrates within dermis and subcutaneous tissue. Epidermotropism may be present. Neoplastic infiltrates may surround the blood vessels and destroy them causing necrosis. Necrosis hinders the immunophenotyping. Involved field radiotherapy (IF-RT) 50-55 Gy is the treatment of choice for the cases with limited disease (Ann Arbor I-II) plus CNS prophylaxis in cases with a higher risk of CNS involvement (nasal cavity, sinuses, orbit and testes). More advanced cases (Ann Arbor III-IV) and relapses require combined treatment with radio- and chemotherapy according to the CHOP regimen or multidrug schemes with $L$-asparaginase and etoposide. The prognosis is very grave. The median survival is 27 months provided the lesions are limited to the skin. If extracutaneous tissues are infiltrated the median survival time drops to 5 months. No more than $25 \%$ of the patients live longer than 5 years $[7,65,66]$.

\section{Primary cutaneous mature B-cell neoplasms}

Primary cutaneous mature B-cell neoplasms comprise approximately $25 \%$ of all primary CTCLs.

\section{Primary cutaneous follicle centre lymphoma}

Primary cutaneous follicle centre lymphoma (PCFCL) affects mainly adults. The median age of diagnosis is 51 years of age. This lymphoma presents with elevated flat papules or nodular infiltrates with an erythematous base. The lesions occur alone or in groups, mainly on the head and trunk, less often on the lower extremities. Erythematous papules and plaques may predate the formation of tumours for several years. Histopatological examination demonstrates nodular, diffuse or mixed infiltrates within dermis which spare the epidermis. Centrocytes are the dominant type of cells with an addition of centroblasts. Neoplastic cells present with the following phenotype: CD20+, CD79a+, bcl-6+, CD10+, CD5-, CD43-. The treatment strategies for PCFCL are similar to those for primary cutaneous marginal zone lymphoma. The prognosis is good regardless of the type of the neoplastic infiltration (nodular or diffuse), number of centroblasts, presence of grouped or multifocal lesions. A 5-year survival rate is over $95 \%[7,62,67-73]$.

\section{Primary cutaneous marginal zone lymphoma}

Primary cutaneous marginal zone B-cell lymphoma (PCMZL) is characterised by the presence of multiple livid-red nodules, plaques and tumours in the skin of the trunk and shoulders. The lesions do not show a tendency for ulceration. The skin lesion can be recurrent, but lymph node or visceral involvement is seldom described. The lesions can regress spontaneously. A probable etiopathogenetic relationship between this lymphoma and Borrelia burgdorferi infection is emphasised, especially in the European population. Skin biopsy specimens present with nodular or diffuse infiltrates, consisting of small lymphocytes, cells from the marginal zone of the reactive lymphatic follicles, as well as lymphoplasmatic and plasmatic cells with admixed centroblasts, immunoblasts, histiocytes and eosinophils. The epidermis is always free of the disease. Marginal zone B cells have a distinct phenotype: CD20+, CD79a+, bcl-2+, but CD5-, CD10-, bcl-6-. Patients with confirmed Borrelia burgdorferi infection should start the treatment with antibiotics (V-penicillin or doxycycline). Solitary or sparse lesions can be removed surgically or with radiotherapy with a cumulative dose of 30-45 Gy. Multiple skin lesions or relapse may be treated with topical steroids or glucocorticosteroid injections directly into the lesion, other medications can also be injected into the lymphomatous infiltrates, namely IFN- $\alpha$ 1-6 MU 3 times a week or rituximab 5-30 mg, 1-3 times a week, 1-2 cycles every 4 weeks. Chemotherapy is occasionally used in cases with generalised skin involvement or in visceral infiltration. In 
such case, monotherapy with chlorambucil is recommended, or polychemotherapy according to the following regimen: rituximab $\left(375 \mathrm{mg} / \mathrm{m}^{2}\right.$ i.v. every week for 4 consecutive weeks) in combination with COP (cyclophosphamide, vincristine, and prednisone) or with (HOP. The prognosis is good, CR is achievable in approximately $50 \%$ of the patients and a 5-year survival rate is almost 100\% [7, 67-73].

\section{Primary cutaneous diffuse large B-cell lymphoma, leg type}

Primary cutaneous LBCL, leg type, is mainly a disease of elderly women. The median age at diagnosis is 70 years. Clinical presentation includes red or livid-red tumours on one or both legs. Extracutaneous lesions are often seen. The histopathological evaluation shows monomorphic, diffuse infiltration of the dermis, with no involvement of the epidermis. Neoplastic cells express CD20+, CD79a+, bcl-2+, CD10-, bcl-6+/-, as well as IRF4/ MUM1+ and FOX-P1+. Polychemotherapy is recommended for cases with the disease limited to the skin. Rituximab with CHOP is used with adjuvant local radiotherapy. Radiotherapy alone is used when chemotherapy is contraindicated. Intravenous rituximab $375 \mathrm{mg} / \mathrm{m}^{2}$ every week for 4-8 weeks may provide a promising second-line therapy, but requires further confirmative studies. Rituximab can also be used in two i.v. infusions of $250 \mathrm{mg} / \mathrm{m}^{2}$ on days 1 and 8 plus a single dose of Yitrium-90 ibritumomab tiuxetan (99Y-IT) 11-15 MBq/kg on day 8.

The prognosis is grave, with multiple skin lesions at the diagnosis being an unfavourable prognostic factor. Recent studies report a 100\% 5-year survival rate in patients with solitary tumours, but only $45 \%$ and $36 \%$ in patients with multiple tumours located on one leg or both legs, respectively [7, 74-81].

\section{Conflict of interest}

The authors declare no conflict of interest.

\section{References}

1. Prince HM, Whittaker S, Hoppe RT. How I treat mycosis fungoides and Sézary syndrome. Blood 2009; 114: 4337-53.

2. Gniadecki R. Zasady leczenia pierwotnych chłoniaków skóry. Onkol Prakt Klin 2009; 5: 103-8.

3. Kim EJ, Hess S, Richardson SK, et al. Immunopathogenesis and therapy of cutaneous T cell lymphoma. J Clin Invest 2005; 115: 798-812.

4. Aschebrook-Kilfoy B, Cocco P, La Vecchia C, et al. Medical history, lifestyle, family history, and occupational risk factors for mycosis fungoides and Sezary syndrome: The InterLymph Non-Hodgkin Lymphoma Subtypes Project. JNCI Monographs 2014; 2014: 98-105.

5. Wilcox RA. Cutaneous T-cell lymphoma: 2014 Update on diagnosis, risk-stratification, and management. Am J Hematol 2014; 89: 837-51.

6. Vonderheid EC, Bernengo MG, Burg G, et al. Update on erythrodermic cutaneous T-cell lymphoma: report of the In- ternational Society for Cutaneous Lymphomas. J Am Acad Dermatol 2002; 46: 95-106.

7. Willemze R, Jaffe ES, Burg G, et al. WHO-EORTC classification for cutaneous lymphomas. Blood 2005; 105: 3768-85.

8. Gonzalez CL, Medeiros LJ, Braziel RM, Jaffe ES. T-cell lymphoma involving subcutaneous tissue. A clinicopathologic entity commonly associated with hemophagocytic syndrome. Am J Surg Pathol 1991; 15: 17-27.

9. Burg G, Dummer R, Wilhelm M, et al. A subcutaneous deltapositive T-cell lymphoma that produces interferon gamma. N Engl J Med 1991; 325: 1078-81.

10. Salhany KE, Macon WR, Choi JK, et al. Subcutaneous panniculitis-like T-cell lymphoma: clinicopathologic, immunophenotypic, and genotypic analysis of alpha/beta and gamma/ delta subtypes. Am J Surg Pathol 1998; 22: 881-93.

11. Santucci M, Pimpinelli N, Massi D, et al. Cytotoxic/natural killer cell cutaneous lymphomas. Report of EORTC Cutaneous Lymphoma Task Force Workshop. Cancer 2003; 97 : 610-27.

12. Hoque SR, Child FJ, Whittaker SJ, et al. Subcutaneous panniculitis-like T-cell lymphoma: a clinicopathological, immunophenotypic and molecular analysis of six patients. $\mathrm{Br}$ J Dermatol 2003; 148: 516-25.

13. Massone C, Chott A, Metze D, et al. Subcutaneous, blastic natural killer (NK), NK/T-cell, and other cytotoxic lymphomas of the skin: a morphologic, immunophenotypic, and molecular study of 50 patients. Am J Surg Pathol 2004; 28: 719-35.

14. Hoppe RT, Abel EA, Deneau DG, Price NM. Mycosis fungoides: management with topical nitrogen mustard. J Clin Oncol 1987; 5: 1796-803.

15. Vonderheid EC, Tan ET, Kantor AF, Shrager L, Micaily B, Van Scott EJ. Long-term efficacy, curative potential, and carcinogenicity of topical mechlorethamine chemotherapy in cutaneous T cell lymphoma. J Am Acad Dermatol 1989; 20: 416-28.

16. Kim YH, Martinez G, Varghese A, Hoppe RT. Topical nitrogen mustard in the management of mycosis fungoides: update of the Stanford experience. Arch Dermatol 2003; 139: 165-73.

17. Zackheim HS, Kashani-Sabet M, Amin S. Topical corticosteroids for mycosis fungoides. Experience in 79 patients. Arch Dermatol 1998; 134: 949-54.

18. Herrmann JJ, Roenigk HH, Hurria A, et al. Treatment of mycosis fungoides with photochemotherapy (PUVA): long-term follow-up. J Am Acad Dermatol 1995; 33: 234-42.

19. Berthelot C, Rivera A, Duvic M. Skin directed therapy for mycosis fungoides: a review. J Drugs Dermatol 2008; 7: 655-66.

20. Rupoli S, Barulli S, Guiducci B, et al. Low dose interferonalpha2b combined with PUVA is an effective treatment of early stage mycosis fungoides: results of a multicenter study. Cutaneous-T Cell Lymphoma Multicenter Study Group. Haematologica 1999; 84: 809-13.

21. Stadler R, Otte HG, Luger T, et al. Prospective randomized multicenter clinical trial on the use of interferon -2a plus acitretin versus interferon -2a plus PUVA in patients with cutaneous T-cell lymphoma stages I and II. Blood 1998; 92: 3578-81.

22. Thomsen K, Hammar H, Molin L, Volden G. Retinoids plus PUVA (RePUVA) and PUVA in mycosis fungoides, plaque stage. A report from the Scandinavian Mycosis Fungoides Group. Acta Derm Venereol 1989; 69: 536-8.

23. Chmielowska E, Studziński M, Giebel S, et al. Follow-up of patients with mycosis fungoides after interferon alpha2b treatment failure. Postep Derm Alergol 2015; 32: 67-72. 
24. Talpur R, Ward S, Apisarnthanarax N, Breuer-Mcham J, Duvic M. Optimizing bexarotene therapy for cutaneous T-cell lymphoma. J Am Acad Dermatol 2002; 47: 672-84.

25. Duvic M, Hymes K, Heald P, et al. Bexarotene is effective and safe for treatment of refractory advanced-stage cutaneous T-cell lymphoma: multinational phase II-III trial results. J Clin Oncol 2001; 19: 2456-71.

26. Duvic M, Martin AG, Kim Y, et al. Phase 2 and 3 clinical trial of oral bexarotene (Targretin capsules) for the treatment of refractory or persistent early-stage cutaneous T-cell lymphoma. Arch Dermatol 2001; 137: 581-93.

27. Gniadecki R, Assaf C, Bagot M, et al. The optimal use of bexarotene in cutaneous T-cell lymphoma. Br J Dermatol 2007; 157: 433-40.

28. Breneman D, Duvic M, Kuzel T, Yocum R, Truglia J, Stevens VJ. Phase 1 and 2 trial of bexarotene gel for skin-directed treatment of patients with cutaneous T-cell lymphoma. Arch Dermatol 2002; 138: 325-32.

29. Sokolowska-Wojdylo M, Florek A, Zaucha JM, et al. Polish Lymphoma Research Group Experience With Bexarotene in the Treatment of Cutaneous T-Cell Lymphoma. Am J Ther 2014.

30. Quirós PA, Jones GW, Kacinski BM, et al. Total skin electron beam therapy followed by adjuvant psoralen/ultravioletA light in the management of patients with T1 and T2 cutaneous T-cell lymphoma (mycosis fungoides). Int J Radiat Oncol Biol Phys 1997; 38: 1027-35.

31. Zackheim HS, Kashani-Sabet M, McMillan A. Low-dose methotrexate to treat mycosis fungoides: a retrospective study in 69 patients. J Am Acad Dermatol 2003; 49: 873-8.

32. McDonald CJ, Bertino JR. Treatment of mycosis fungoides lymphoma: effectiveness of infusions of methotrexate followed by oral citrovorum factor. Cancer Treat Rep 1978; 62: 1009-14.

33. Avilés A, Nambo MJ, Neri N, et al. Interferon and low dose methotrexate improve outcome in refractory mycosis fungoides/Sézary syndrome. Cancer Biother Radiopharm 2007; 22: 836-40.

34. Mann BS, Johnson JR, He K, et al. Vorinostat for treatment of cutaneous manifestations of advanced primary cutaneous T-cell lymphoma. Clin Cancer Res 2007; 13: 2318-22.

35. Piekarz RL, Frye R, Prince HM, et al. Phase 2 trial of romidepsin in patients with peripheral T-cell lymphoma. Blood 2011; 117: 5827-34.

36. Prince HM, Bishton MJ, Johnstone RW. Panobinostat (LBH589): a potent pan-deacetylase inhibitor with promising activity against hematologic and solid tumors. Future Oncol 2009; 5: 601-12.

37. Gimsing P. Belinostat: a new broad acting antineoplastic histone deacetylase inhibitor. Expert Opin Investig Drugs 2009; 18: 501-8.

38. Bernengo MG, Quaglino P, Comessatti A, et al. Low-dose intermittent alemtuzumab in the treatment of Sézary syndrome: clinical and immunologic findings in 14 patients. Haematologica 2007; 92: 784-94.

39. Enblad G, Hagberg H, Erlanson M, et al. A pilot study of alemtuzumab (anti-CD52 monoclonal antibody) therapy for patients with relapsed or chemotherapy-refractory peripheral T-cell lymphomas. Blood 2004; 103: 2920-4.

40. Kennedy GA, Seymour JF, Wolf M, et al. Treatment of patients with advanced mycosis fungoides and Sézary syndrome with alemtuzumab. Eur J Haematol 2003; 71: 250-6.

41. Thursky KA, Worth LJ, Seymour JF, Miles Prince H, Slavin MA Spectrum of infection, risk and recommendations for prophylaxis and screening among patients with lymphoprolif- erative disorders treated with alemtuzumab. Br J Haematol 2006; 132: 3-12.

42. Gautschi O, Blumenthal N, Streit M, Solenthaler M, Hunziker T, Zenhäusern R. Successful treatment of chemotherapy-refractory Sézary syndrome with alemtuzumab (Campath-1H). Eur J Haematol 2004; 72: 61-3.

43. Kaye FJ, Bunn PA, Steinberg SM, et al. A randomized trial comparing combination electron-beam radiation and chemotherapy with topical therapy in the initial treatment of mycosis fungoides. N Engl J Med 1989; 321: 1784-90.

44. Bartlett JB, Dredge K, Dalgleish AG. The evolution of thalidomide and its IMiD derivatives as anticancer agents. Nature Reviews Cancer 2004; 4: 314-22.

45. Querfeld C, Rosen ST, Guitart J, et al. Phase II multicenter trial of lenalidomide: clinical and immunomodulatory effects in patients with CTCL. Blood 2014; 123: 1159-66.

46. Krieg AM. Therapeutic potential of Toll-like receptor 9 activation. Nat Rev Drug Discov 2006; 5: 471-84.

47. Kim YH, Girardi M, Duvic M, et al. Phase I trial of a Toll-like receptor 9 agonist, PF-3512676 (CPG 7909), in patients with treatment-refractory, cutaneous T-cell lymphoma. J Am Acad Dermatol 2010; 63: 975-83.

48. Kim YH, Duvic M, Obitz E, et al. Clinical efficacy of zanolimumab (HuMax-CD4): two phase 2 studies in refractory cutaneous T-cell lymphoma. Blood 2007; 109: 4655-62.

49. Agar NS, Wedgeworth E, Crichton S, et al. Survival outcomes and prognostic factors in mycosis fungoides/Sézary syndrome: validation of the revised International Society for Cutaneous Lymphomas/European Organisation for Research and Treatment of Cancer staging proposal. J Clin Oncol 2010; 28: 4730-9.

50. Kempf W, Kazakov DV, Kerl K. Cutaneous lymphomas: an update. Part 1: T-cell and natural killer/T-cell lymphomas and related conditions. Am J Dermatopathol 2014; 36: 105-23.

51. Bekkenk MW, Geelen FA, van Voorst Vader PC, et al. Primary and secondary cutaneous CD30(+) lymphoproliferative disorders: a report from the Dutch Cutaneous Lymphoma Group on the long-term follow-up data of 219 patients and guidelines for diagnosis and treatment. Blood 2000; 95: 3653-61.

52. Vonderheid EC, Sajjadian A, Kadin ME. Methotrexate is effective therapy for lymphomatoid papulosis and other primary cutaneous CD30-positive lymphoproliferative disorders. J Am Acad Dermatol 1996; 34: 470-81.

53. Kadin ME, Carpenter C. Systemic and primary cutaneous anaplastic large cell lymphomas. Semin Hematol 2003; 40: 244-56.

54. Willemze R, Kerl H, Sterry W, et al. EORTC classification for primary cutaneous lymphomas: a proposal from the Cutaneous Lymphoma Study Group of the European Organization for Research and Treatment of Cancer. Blood 1997; 90: 354-71.

55. Grange F, Hedelin G, Joly P, et al. Prognostic factors in primary cutaneous lymphomas other than mycosis fungoides and the Sézary syndrome. The French Study Group on Cutaneous Lymphomas. Blood 1999; 93: 3637-42.

56. Beljaards RC, Meijer CJ, Van der Putte SC, et al. Primary cutaneous T-cell lymphoma: clinicopathological features and prognostic parameters of 35 cases other than mycosis fungoides and CD30-positive large cell lymphoma. J Pathol 1994; 172: 53-60.

57. Bekkenk MW, Vermeer MH, Jansen PM, et al. Peripheral Tcell lymphomas unspecified presenting in the skin: analysis of prognostic factors in a group of 82 patients. Blood 2003; 102: 2213-9. 
58. Burg G, Kempf W, Cozzio A, et al. WHO/EORTC classification of cutaneous lymphomas 2005: histological and molecular aspects. J Cutan Pathol 2005; 32: 647-74.

59. Berti E, Tomasini D, Vermeer MH, Meijer CJ, Alessi E, Willemze R. Primary cutaneous CD8-positive epidermotropic cytotoxic T cell lymphomas. A distinct clinicopathological entity with an aggressive clinical behavior. Am J Pathol 1999; 155: 483-92.

60. Agnarsson BA, Vonderheid EC, Kadin ME. Cutaneous T cell lymphoma with suppressor/cytotoxic (CD8) phenotype: identification of rapidly progressive and chronic subtypes. J Am Acad Dermatol 1990; 22: 569-77.

61. de Wolf-Peeters C, Achten R. gammadelta T-cell lymphomas: a homogeneous entity? Histopathology 2000; 36: 294-305.

62. Kütting B, Bonsmann G, Metze D, Luger TA, Cerroni L. Borrelia burgdorferi-associated primary cutaneous B cell lymphoma: complete clearing of skin lesions after antibiotic pulse therapy or intralesional injection of interferon alfa-2a. J Am Acad Dermatol 1997; 36: 311-4.

63. Toro JR, Liewehr DJ, Pabby N, et al. Gamma-delta T-cell phenotype is associated with significantly decreased survival in cutaneous T-cell lymphoma. Blood 2003; 101: 3407-12.

64. Jaffe ES, Krenacs L, Raffeld M. Classification of cytotoxic Tcell and natural killer cell lymphomas. Semin Hematol 2003; 40: $175-84$.

65. Cheung MM, Chan JK, Lau WH, et al. Primary non-Hodgkin's lymphoma of the nose and nasopharynx: clinical features, tumor immunophenotype, and treatment outcome in 113 patients. J Clin Oncol 1998; 16: 70-7.

66. Bekkenk MW, Jansen PM, Meijer CJ, Willemze R. CD56+ hematological neoplasms presenting in the skin: a retrospective analysis of 23 new cases and 130 cases from the literature. Ann Oncol 2004; 15: 1097-108.

67. Mielke V, Wolff HH, Winzer M, Sterry W. Localized and disseminated pagetoid reticulosis. Diagnostic immunophenotypical findings. Arch Dermatol 1989; 125: 402-6.

68. Zenahlik P, Fink-Puches R, Kapp KS, Kerl H, Cerroni L. Therapy of primary cutaneous B-cell lymphomas. Hautarzt 2000; 51: 19-24.

69. Kirova YM, Piedbois Y, Le Bourgeois JP. Radiotherapy in the management of cutaneous B-cell lymphoma. Our experience in 25 cases. Radiother Oncol 1999; 52: 15-8.

70. Heinzerling L, Dummer R, Kempf W, Schmid MH, Burg G. Intralesional therapy with anti-CD20 monoclonal antibody rituximab in primary cutaneous B-cell lymphoma. Arch Dermatol 2000; 136: 374-8.

71. Paul T, Radny P, Kröber SM, Paul A, Blaheta HJ, Garbe C. Intralesional rituximab for cutaneous B-cell lymphoma. Br J Dermatol 2001; 144: 1239-43.

72. Voss N, Kim-Sing C. Radiotherapy in the treatment of dermatologic malignancies. Dermatol Clin 1998; 16: 313-20.

73. Smith BD, Glusac EJ, McNiff JM, et al. Primary cutaneous B-cell lymphoma treated with radiotherapy: a comparison of the European Organization for Research and Treatment of Cancer and the WHO classification systems. J Clin Oncol 2004; 22: 634-9.

74. Dummer R, Kempf W, Hess Schmid M, Häffner A, Burg G. Therapy of cutaneous lymphoma: current practice and future developments. Onkologie 2003; 26: 366-72.

75. Heinzerling LM, Urbanek M, Funk JO, et al. Reduction of tumor burden and stabilization of disease by systemic therapy with anti-CD20 antibody (rituximab) in patients with primary cutaneous B-cell lymphoma. Cancer 2000; 89: 1835-44.
76. Grange F, Bekkenk MW, Wechsler J, et al. Prognostic factors in primary cutaneous large B-cell lymphomas: a European multicenter study. J Clin Oncol 2001; 19: 3602-10.

77. Bekkenk MW, Vermeer MH, Geerts ML, et al. Treatment of multifocal primary cutaneous B-cell lymphoma: a clinical follow-up study of 29 patients. J Clin Oncol 1999; 17: 2471-8.

78. Vermeer MH, Geelen FA, van Haselen CW, et al. Primary cutaneous large B-cell lymphomas of the legs. A distinct type of cutaneous B-cell lymphoma with an intermediate prognosis. Dutch Cutaneous Lymphoma Working Group. Arch Dermatol 1996; 132: 1304-8.

79. Brogan BL, Zic JA, Kinney MC, Hu JY, Hamilton KS, Greer JP. Large B-cell lymphoma of the leg: clinical and pathologic characteristics in a North American series. J Am Acad Dermatol 2003; 49: 223-8.

80. Ferreri AJ, Campo E, Seymour JF, et al. Intravascular lymphoma: clinical presentation, natural history, management and prognostic factors in a series of 38 cases, with special emphasis on the 'cutaneous variant'. Br J Haematol 2004; 127: 173-83.

81. Teresiak-Mikołajczak E, Szymańska M, Czarnecka-Operacz $M$. A case of diffuse large B-cell lymphoma misdiagnosed as an erysipelas of the face. Postep Derm Alergol 2013; 30: 268-70. 